\title{
Crystal Structure of Barium Hydrogen Orthophosphate
}

\author{
Gordon Burley
}

\begin{abstract}
The structure of anhydrous $\mathrm{BaHPO}_{4}$ was determined from three Fourier projections. The unit cell is orthorhombic with the space group $\mathrm{Pn}_{1} \mathrm{a}-\mathrm{No}$. 33. The cell dimensions are $a=14.12, b=17.15$, and $c=4.59 \mathrm{~A}$, and it contains twelve formula units. Each Ba atom has a coordination polyhedron of ten oxygen atoms, being bonded to four phosphate tetrahedra by edge sharing and to two more by corner sharing of oxygen atoms. The phosphate groups are in separate tetrahedra, linked by hydrogen bonding to form continuous chains.
\end{abstract}

\section{Introduction}

The crystal structure of anhydrous barium hydrogen phosphate, $\mathrm{BaHPO}_{4}$, was investigated as part of a program of systematic study of orthophosphate structures. Recent publication of the results of a structure determination of $\mathrm{CaHPO}_{4}$ (monetite) $[1]^{1}$ made it advisable to refine the $\mathrm{BaHPO}_{4}$ structure to such an extent as to allow an examination of the relationship between the two.

\section{Experimental Techniques}

The crystals used in this investigation were grown at the interface of a solution of $\mathrm{Ba}_{3}\left(\mathrm{PO}_{4}\right)_{2}$ covered by a layer of dilute $\mathrm{H}_{3} \mathrm{PO}_{4}$. The morphology of the crystals is that of a horizontal prism on $a$, with average diagonal dimension of $0.35 \mathrm{~mm}$ and thickness of about $0.07 \mathrm{~mm}$.

Oscillation and Weissenberg photographs were taken about the principal axes using $\mathrm{Cu}$ and $\mathrm{Mo}$ radiation. Additional data was also obtained from a precession photograph of the $0 k l$ reflections, using Mo radiation. Intensity data was obtained with a Wiebenga-Nonius integrating Weissenberg camera and a densitometer adapted for the purpose. All reflections were corrected for Lorentz and polarization factors by the method of Lu [2].

\section{Structure}

\subsection{Cell Dimensions and Space Group}

According to Groth [3], De Shulten reported anhydrous $\mathrm{BaHPO}_{4}$ as orthorhombic, in the form of short prisms, and with axial ratios of $a: b: c=$ $0.7133: 1: 0.8117$.

In the present work the $\mathrm{BaHPO}_{4}$ unit cell was found to be orthorhombic with space group Pn2 $2_{1}$ a No. 33 [4]. The observed reflection conditions were

$$
\begin{aligned}
& 0 k l: k+l=2 n, \\
& h k 0: \quad h=2 n .
\end{aligned}
$$

From single crystal photographs, the cell dimensions were obtained as

\footnotetext{
1. Italicized figures in brackets indicate the literature references at the end of this paper.
}

$$
\begin{aligned}
& a=14.12 \pm 0.03 \mathrm{~A}, \\
& b=17.15 \pm 0.03 \mathrm{~A}, \\
& c=4.59 \pm 0.02 \mathrm{~A} .
\end{aligned}
$$

Relative intensities of the layer lines on oscillation photographs strongly suggested a pseudocell having dimensions $a / 2, b / 3, c$. This is somewhat more pronounced in the $b$ direction than along $a$.

Cell dimensions similar to those obtained here, with the same indication of a smaller cell, were given by Bengtsson [5], but the space group Pecn suggested by him did not agree with our observed reflection conditions.

A preliminary AEC paper on this structure by $\mathrm{R}$. C. L. Mooney $[6]$ was recently declassified and made available for inspection. This previous work was based on the pseudocell derived from powder diffraction data and assigned oxygen parameters on the basis of space group symmetry alone. Only qualitative single crystal intensity data was used. The barium parameters are in excellent agreement with those obtained in this investigation, although oxygen positions are different. This is primarily due to the fact that all reflections contain a barium contribution, and the comparatively small variation in the calculated intensity, resulting from the assumption of a small oxygen shift could not be detected with the qualitative data used.

On the basis of the larger unit cell established in this investigation, there are 12 formula units in the cell and all atoms are in the fourfold general positions

$$
x, y, z ; \bar{x}, \frac{1}{2}+y, \bar{z} ; \frac{1}{2}-x, \frac{1}{2}+y, \frac{1}{2}+z ; \frac{1}{2}+x, y, \frac{1}{2}-z .
$$

The space group is proposed on the basis of the observable scattering contribution of all atoms, but the almost negligible scattering of hydrogen atoms precludes their inclusion in the original selection of symmetry elements. The calculated density is 4.170 $\mathrm{g} / \mathrm{cm}^{3}$, compared with a reported value of 4.165 $\mathrm{g} / \mathrm{cm}^{3}$ [3].

\subsection{Absorption Corrections}

The $h k 0$ reflections were obtained from Weissen. berg photographs using $\mathrm{Mo}_{\alpha} \mathrm{K}_{\alpha}$ radiation, since the largest dimension of the crystal was well below the optimum size calculated from linear absorption data 
for this wavelength. The $0 k l$ pattern was obtained on a precession camera with the largest cristal face normal to the incident beam. Only the usual Lorentz-polarization correction was applied. For the $h 0 l$ zone of reflections, it was necessary to use an absorption correction because of the geometry of the crystal. This was done by setting up a graph of the correction factor as a function of $\sin \theta / \lambda$ and obtaining the appropriate interpolated value for each $h 0 l$ reflection. The graph was constructed from a com:parison of the observed $h 00$ reffections on the $h 0 l$ films with the calculated values, used as the standard, available from the $h k 0$ projection. A separate straight line relationship held for each of three separate films and the agreement for the three flms was within better than 5 percent for all observed reflections. This scaling assumed approximate circular cross section of a cylindrical specimen and is essentially an absorption correction approximation. In order to evaluate this approximation method, the absorption for eight reflections, widely differing in intensity and position, was separately calculated by the geometrical absorption correction method of Evans [7]. The agreement was within 8 percent, and deviated in both directions. Therefore, the values of the $h 0 l$ intensities, corrected for absorption and scaled by the above method, were used in the calculations, but substantially only as a secondary check to reject a grossly inaccurate structure.

\subsection{Structure Determination}

The presence of the short $c$ axis suggested a preliminary trial projection on the 001 plane. Approximate $\mathrm{Pa}$ positions were found from line svntheses along [100] and [010] and a Fatterson projection. A Fourier projection using only these $\mathrm{Ba}$ parameters showed the position of the P atoms. Rows of alternating $\mathrm{Ba}$ atoms and $\mathrm{P}$ atoms were alined parallel to the $a$ axis with a separation of $b / 6$ and with an interval between adjacent atoms of the same row of about $a / 4$. The projection was then refined by four successive difference Fourier syntheses, where the coefficients are obtained by subtracting the calculated from the observed structure factor for each index. This indicated that the phosphate tetrahedra were turned approximately $20^{\circ}$ about a rotation axis parallel to the $a$ axis, and that successive tetrabedra in the same row were turned in opposite directions. Because the magnitude of the angle of rotation was of importance in fixing the position of the bydrogen bond, it was determined by calculating structure factors for increments of $10^{\circ}$ rotation of the tetrahedra from $0^{\circ}$ to $90^{\circ}$. A graph of $R$ values versus angle of rotation, with additional calculations at intervals of $2 \mathrm{deg}$ from $18^{\circ}$ to $26^{\circ}$, showed a minimum. at about $21^{\circ}$ (fig. 1). The fnal value of $R$ for the $h k 0$ reflections was 14.4 percent, where $R$ is defined as

$$
\frac{\Sigma\left|\left(\left|F_{o b s}\right|-\left|F_{c a l c}\right|\right)\right|}{\Sigma\left|F_{o b s}\right|} \text {. }
$$

Patterson syntheses, using $h 0 l$ and $0 k l$ data, showed conclusively that all the $\mathrm{Ba}$ and $\mathrm{P}$ atoms on a row parallel to the $a$ axis had almost identical $z$ param-

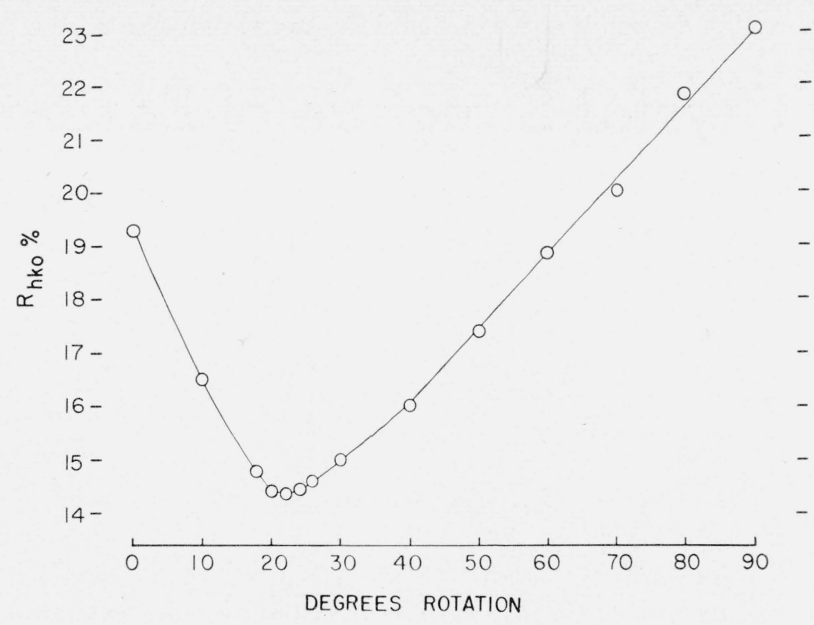

FIGURE 1. Graph of $R$ values for the hk0 zone of reflections versus angle of rotation of the phosphate tetrahedra.

eters, and that each row was separated from its neighbor by about $b / 6$ and $c / 2$. There was overlap of atoms in both the $a$ and $b$ directions and Fourier projections did not resolve individual atoms. For the three independent $\mathrm{Ba}$ atoms, refinement of the z parameters was accomplished by calculation of structure factors for various combinations of Ba positions. The approximate contribution from the other atoms was added to this partial structure factor, and the total matched with the observed data. Several combinations of the three independent parameters gave satisfactory agreement for the $h 0 l$ data, but only one set could also be reconciled with the $0 \mathrm{kl}$ data. A least-squares refinement was attempted, but there was no convergence because of the overlap. Simultaneous adjustment in small increments of all atomic $z$ parameters resulted in final agreement factor $(R)$ values of 17.2 percent for the $h 0 l$ reflections and 14.5 percent for the $0 \mathrm{kl}$ set. The $\mathrm{P}$ to $\mathrm{O}$ distance was assumed constant at $1.56 \mathrm{~A}$ for this purpose. The independent atomic parameters are listed in table 1.

TABLE 1. Cocrdinates of atoms in $\mathrm{BaHPO}_{4}$

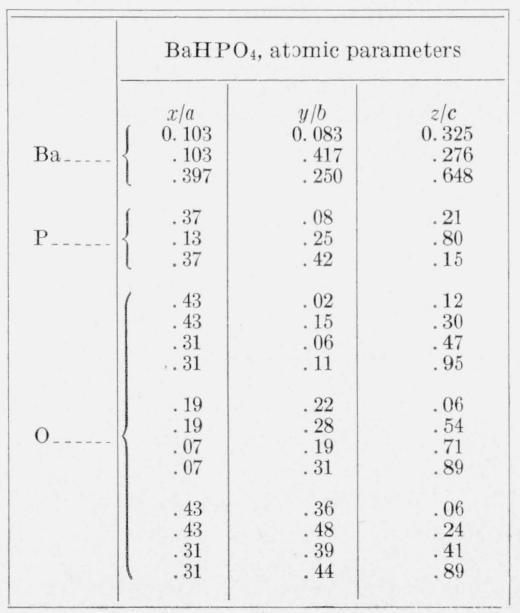


A comparison of observed and calculated structure $\mid$ structure factors. Since each zone of reflections was factors is given in table 2. All intensities were treated independently, all row lines appear twice in measured on a relative scale for each zone of reflec- this table, for these reflections are observed separately tion and scaled by comparison with the calculated on two films.

TABLE 2. Comparison of calculated and observed structure factors for $\mathrm{BaHPO}_{4}$

\begin{tabular}{|c|c|c|c|c|c|c|c|c|c|c|c|c|c|c|}
\hline$h$ & $k$ & $l$ & $F_{0}$ & $F_{c}$ & $h$ & $k$ & $l$ & $F_{o}$ & $F_{c}$ & $h$ & $k$ & $l$ & $F_{o}$ & $F_{c}$ \\
\hline 00 & 00 & 02 & 76 & $84-$ & 13 & 00 & 03 & 15 & $11-$ & 00 & 00 & 02 & 105 & $84-$ \\
\hline 00 & 00 & 04 & 12 & 11 & 13 & 00 & 04 & 10 & $18-$ & 00 & 00 & 04 & 13 & 11 \\
\hline 01 & 00 & 01 & 0 & 13 & 14 & 00 & 00 & 54 & $50-$ & 00 & 00 & 06 & 20 & 19 \\
\hline 01 & 00 & 02 & 16 & $9-$ & 14 & 00 & 01 & 30 & $29-$ & 00 & 01 & 01 & 0 & 9 \\
\hline 01 & 00 & 03 & 21 & 17 & 14 & 00 & 02 & 29 & 31 & 00 & 01 & 01 & & \\
\hline 01 & 00 & 04 & 24 & $20-$ & 14 & 00 & 03 & 10 & 14 & $\begin{array}{l}00 \\
00\end{array}$ & 01 & $\begin{array}{l}03 \\
05\end{array}$ & $\begin{array}{l}36 \\
32\end{array}$ & $\begin{array}{l}43- \\
40\end{array}$ \\
\hline 01 & 00 & 05 & 33 & $32-$ & 15 & 00 & 01 & 0 & $I_{2}^{1+}$ & 00 & $\begin{array}{l}01 \\
02\end{array}$ & $\begin{array}{l}05 \\
02\end{array}$ & $\begin{array}{l}02 \\
22\end{array}$ & 19 \\
\hline 02 & 00 & 00 & $\begin{array}{r}00 \\
0\end{array}$ & 22 & $\begin{array}{l}10 \\
15\end{array}$ & 00 & $\begin{array}{l}01 \\
02\end{array}$ & 0 & $3-$ & 00 & 02 & 04 & 40 & $\begin{array}{l}19 \\
46-\end{array}$ \\
\hline 02 & 00 & 01 & 48 & $80-$ & 16 & 00 & 00 & 46 & $45-$ & 00 & 02 & 06 & 39 & 39 \\
\hline 02 & 00 & 02 & 43 & $44-$ & 16 & 00 & 02 & 67 & 78 & & & & & \\
\hline 02 & 00 & 03 & 0 & $5-$ & 16 & 00 & 02 & 20 & 23 & 00 & 03 & 01 & $\mathrm{vl}$ & $165-$ \\
\hline $\begin{array}{l}02 \\
02\end{array}$ & $\begin{array}{l}00 \\
00\end{array}$ & $\begin{array}{l}03 \\
04\end{array}$ & $\begin{array}{r}0 \\
20\end{array}$ & $5-$ & & & & & & 00 & 03 & 03 & 49 & 49 \\
\hline & 00 & 04 & 20 & $21-$ & & & & & & 00 & 03 & 05 & 10 & 12 \\
\hline 02 & 00 & 05 & 27 & 28 & 00 & 06 & 00 & 130 & $156-$ & 00 & 04 & 02 & 19 & $32-$ \\
\hline 03 & 00 & 01 & 0 & 1 & 00 & 12 & 00 & 136 & 134 & 00 & 04 & 04 & 33 & 42 \\
\hline 03 & 00 & 02 & 0 & 2 & 00 & 18 & 00 & 119 & $93-$ & & & & & \\
\hline & & & & & 02 & 00 & 00 & 0 & 22 & 00 & 04 & 06 & 25 & $37-$ \\
\hline 03 & 00 & 03 & 21 & $12-$ & 02 & 03 & 00 & 86 & $84-$ & 00 & 05 & 01 & 0 & 7 \\
\hline 03 & 00 & 04 & 48 & $36-$ & 02 & 00 & 00 & 00 & 81 & 00 & 05 & 03 & 36 & $30-$ \\
\hline 03 & 00 & 05 & 24 & 20 & 02 & 06 & 00 & 0 & 0 & 00 & 05 & 05 & 27 & 30 \\
\hline 04 & 00 & 00 & 112 & $156-$ & 02 & 09 & 00 & 117 & $102-$ & 00 & 06 & 00 & 123 & $158-$ \\
\hline 04 & 00 & 01 & 38 & $45-$ & 02 & 12 & 00 & 47 & 35 & 00 & 00 & 00 & 120 & 100 \\
\hline & & & & & 02 & 15 & 00 & 81 & $65-$ & 00 & 06 & 02 & 73 & 75 \\
\hline 04 & 00 & 02 & 69 & 98 & 02 & 18 & 00 & 0 & $28-$ & 00 & 06 & 04 & 17 & $24-$ \\
\hline 04 & 00 & 03 & 21 & 26 & & & & & & 00 & 06 & 06 & 14 & $8-$ \\
\hline 04 & 00 & 04 & 0 & 8 & 02 & 21 & 00 & 83 & 74 & 00 & 07 & 01 & 0 & $5-$ \\
\hline 04 & 00 & 05 & 0 & 4 & 04 & 00 & 00 & 81 & $156-$ & 00 & 07 & 03 & 33 & 40 \\
\hline 05 & 00 & 01 & 0 & 2 & 04 & 03 & 00 & 92 & $108-$ & & & & Do & 70 \\
\hline & & & & & 04 & 06 & 00 & 117 & 117 & 00 & 07 & 05 & 27 & $31-$ \\
\hline 05 & 00 & 02 & 0 & 0 & 04 & 09 & 00 & 108 & 86 & 00 & 08 & 02 & 16 & $20-$ \\
\hline 05 & 00 & 03 & 23 & $17-$ & & & & & & 00 & 08 & 04 & 35 & 40 \\
\hline 05 & 00 & 04 & 0 & $5-$ & 04 & 12 & 00 & 127 & $114-$ & 00 & 08 & 06 & 26 & $29-$ \\
\hline 05 & 00 & 05 & 39 & 36 & 04 & 15 & 00 & 52 & $35-$ & 00 & 09 & 01 & 105 & 116 \\
\hline 06 & 00 & 00 & 108 & $103-$ & 04 & 18 & 00 & 105 & 91 & 00 & & & & \\
\hline & & & & 100 & 04 & 21 & 00 & 61 & 47 & 00 & 09 & 03 & 41 & $43-$ \\
\hline 06 & 00 & 01 & 39 & 52 & 06 & 00 & 00 & 78 & $103-$ & 00 & 09 & 05 & 0 & $3-$ \\
\hline 06 & 00 & 02 & 41 & 42 & & & & & & 00 & 10 & 02 & 29 & 20 \\
\hline 06 & 00 & 03 & 0 & 0 & 06 & 03 & 00 & 70 & 90 & 00 & 10 & 04 & 34 & $34-$ \\
\hline 06 & 00 & 04 & 15 & 20 & 06 & 06 & 00 & 63 & 47 & 00 & 11 & 01 & 0 & $8-$ \\
\hline 06 & 00 & 05 & 20 & $20-$ & 06 & 09 & 00 & 69 & $54-$ & & & & & \\
\hline 00 & 00 & OJ & 20 & $20-$ & 06 & 12 & 00 & $\begin{array}{l}83 \\
88\end{array}$ & $\begin{array}{l}5+- \\
70-\end{array}$ & 00 & 11 & 03 & 29 & 33 \\
\hline 07 & 00 & 01 & 0 & 0 & 06 & 15 & 00 & $\begin{array}{l}88 \\
41\end{array}$ & 36 & 00 & $\begin{array}{l}11 \\
11\end{array}$ & $\begin{array}{l}05 \\
05\end{array}$ & $\begin{array}{l}29 \\
26\end{array}$ & $\begin{array}{l}35 \\
34-\end{array}$ \\
\hline 07 & 00 & 02 & 0 & $5-$ & & & & & & 00 & 12 & 00 & 121 & 138 \\
\hline 07 & 00 & 03 & 0 & 1 & 06 & 18 & 00 & 55 & 53 & 00 & 12 & 02 & 85 & $85-$ \\
\hline 07 & 00 & 04 & 34 & 30 & 08 & 00 & 00 & 44 & 43 & 00 & 12 & 04 & 14 & 10 \\
\hline 07 & 00 & 05 & 0 & $1-$ & 08 & 03 & 00 & 78 & 104 & & & & 14 & \\
\hline & & & & & 08 & 06 & 00 & 78 & $70-$ & 00 & 12 & 06 & 13 & 8 \\
\hline 08 & 00 & 00 & 44 & 43 & 08 & 09 & 00 & 114 & $114-$ & 00 & 13 & 01 & 0 & 6 \\
\hline 08 & 00 & 01 & 84 & 100 & & & & & & 00 & 13 & 03 & 28 & $32-$ \\
\hline 08 & 00 & 02 & 38 & $53-$ & 08 & 12 & 00 & 61 & 56 & 00 & 14 & 02 & 13 & 18 \\
\hline 08 & 00 & 03 & 34 & $31-$ & 08 & 15 & 00 & 94 & 86 & 00 & 14 & 04 & 26 & $36-$ \\
\hline 08 & 00 & 04 & 0 & 2 & 08 & 18 & 00 & 58 & $57-$ & & & & & 50 \\
\hline & & & & & 10 & 00 & 00 & 83 & 105 & 00 & 15 & 01 & 98 & $114-$ \\
\hline 08 & 00 & 05 & 10 & $10-$ & 10 & 03 & 00 & 0 & $10-$ & 00 & 15 & 03 & 37 & 33 \\
\hline 09 & 00 & 01 & 0 & 1 & & & & & & 00 & 16 & 02 & 26 & $21-$ \\
\hline 09 & 00 & 02 & 0 & $6-$ & 10 & 06 & 00 & 70 & $85-$ & 00 & 16 & 04 & 28 & 32 \\
\hline 09 & 00 & 03 & 0 & 10 & 10 & 09 & 00 & 0 & $4-$ & 00 & 17 & $\begin{array}{l}04 \\
01\end{array}$ & $\begin{array}{r}20 \\
0\end{array}$ & $\begin{array}{r}52 \\
2\end{array}$ \\
\hline 09 & 00 & 04 & 12 & $16-$ & 10 & 12 & 00 & 72 & 67 & & & & & \\
\hline & & & & & 10 & 15 & 00 & 0 & $15-$ & 00 & 17 & 03 & 17 & $23-$ \\
\hline 09 & 00 & 05 & 25 & $32-$ & $\begin{array}{l}10 \\
10\end{array}$ & $\begin{array}{l}10 \\
18\end{array}$ & 00 & 58 & $51-$ & 00 & $\begin{array}{l}11 \\
18\end{array}$ & $\begin{array}{l}03 \\
00\end{array}$ & $\begin{array}{l}11 \\
85\end{array}$ & $96-$ \\
\hline 10 & 00 & 00 & 106 & 105 & & & & & & 00 & $\begin{array}{l}10 \\
18\end{array}$ & 02 & $\begin{array}{l}00 \\
62\end{array}$ & 73 \\
\hline 10 & 00 & 01 & 0 & $17-$ & 12 & 00 & 00 & 0 & $1-$ & 00 & 19 & 01 & 0 & $7-$ \\
\hline 10 & 00 & 02 & 36 & $30-$ & 12 & 03 & 00 & 97 & $108-$ & 00 & 19 & 03 & 18 & 30 \\
\hline 10 & 00 & 03 & 0 & $11-$ & 12 & 06 & 00 & 0 & 21 & & & & & \\
\hline & & & & & 12 & 09 & 00 & 86 & 103 & 60 & 20 & 02 & 0 & $15-$ \\
\hline $\begin{array}{l}10 \\
11\end{array}$ & 00 & 04 & $\begin{array}{r}20 \\
0\end{array}$ & $19-$ & 12 & 12 & 00 & 0 & 9 & 00 & 21 & 01 & 66 & 77 \\
\hline 11 & $\begin{array}{l}00 \\
00\end{array}$ & $\begin{array}{l}01 \\
02\end{array}$ & $\begin{array}{l}0 \\
0\end{array}$ & ${ }_{6}^{2}-$ & 19 & 15 & & & & 00 & 21 & 03 & 27 & $34-$ \\
\hline 11 & 00 & 03 & 0 & 6 & 12 & 15 & 00 & 86 & $101-$ & 00 & 22 & 02 & 0 & $5-$ \\
\hline 11 & 00 & 04 & 19 & $16-$ & $\begin{array}{l}14 \\
14\end{array}$ & 00 & 00 & 44 & $50-$ & 00 & 23 & 01 & 0 & 4 \\
\hline 12 & & 00 & 0 & 1 & $\begin{array}{l}14 \\
14\end{array}$ & $\begin{array}{l}03 \\
06\end{array}$ & 00 & 39 & $44-$ & 00 & 2 & 0 & 78 & 80 \\
\hline $\begin{array}{l}12 \\
12\end{array}$ & $\begin{array}{l}00 \\
00\end{array}$ & $\begin{array}{l}00 \\
01\end{array}$ & $\begin{array}{r}0 \\
101\end{array}$ & $\begin{array}{l}1- \\
106-\end{array}$ & $\begin{array}{l}14 \\
14\end{array}$ & $\begin{array}{l}0 \\
09\end{array}$ & $\begin{array}{l}00 \\
00\end{array}$ & $\begin{array}{l}54 \\
33\end{array}$ & $\begin{array}{l}68 \\
40\end{array}$ & 00 & 24 & 00 & 10 & 80 \\
\hline 12 & 00 & 02 & $\begin{array}{r}101 \\
0\end{array}$ & $13-$ & & & & & & & & & & \\
\hline 12 & 00 & 03 & 32 & $28-$ & 14 & 12 & 00 & 42 & $55-$ & & & & & \\
\hline 12 & 00 & 04 & 22 & $20-$ & $\begin{array}{l}16 \\
16\end{array}$ & $\begin{array}{l}00 \\
03\end{array}$ & $\begin{array}{l}00 \\
00\end{array}$ & $\begin{array}{l}50 \\
75\end{array}$ & $\begin{array}{l}45- \\
96\end{array}$ & & & & & \\
\hline 13 & 00 & 01 & 0 & $2-$ & 16 & 06 & 00 & 39 & 42 & & & & & \\
\hline 13 & 00 & 02 & 0 & 6 & 16 & 09 & 00 & 58 & $73-$ & & & & & \\
\hline
\end{tabular}




\subsection{Estimate of Accuracy}

An estimation of the accuracy of the structure determination was made from the final difference map on the $h k 0$ plane by Cruickshank's method $[8,9]$. Assuming isotropic variation, the standard deviations of atomic parameters are

$$
\begin{aligned}
& \mathrm{Ba}=0.018 \mathrm{~A}, \\
& \mathrm{P}=.055 \mathrm{~A}, \\
& \mathrm{O}=.065 \mathrm{~A} .
\end{aligned}
$$

Because of the large uncertainty in the positions of the lighter atoms, no artificial temperature factor was used.

The standard deviations of bond lengths are

$$
\begin{aligned}
& \mathrm{Ba}-\mathrm{O}=0.067 \mathrm{~A}, \\
& \mathrm{P}-\mathrm{O}=.085 \mathrm{~A}, \\
& \mathrm{O}-\mathrm{O}=.091 \mathrm{~A} .
\end{aligned}
$$

\section{Description of Structure}

The unit cell contains 12 formula weights of $\mathrm{BaHPO}_{4}$. All atoms are in general positions that are related by symmetry in sets of four. Consequently, there are only $3 \mathrm{Ba}, 3 \mathrm{P}$, and $12 \mathrm{O}$ atoms with independent parameters. The $x$ and $y$ coordinates of the $\mathrm{Ba}$ atoms are in excellent agreement with those given previously by Bengtsson [5]. The present investigation has contributed the $z$ parameters for the $\mathrm{Ba}$ atoms and the placement of the lighter atoms.

A schematic projection of the structure on the $h k 0$ plane is shown in figure 2 . The height above the base plane where $z=0$ is indicated for each atom in units of $z / 100$.

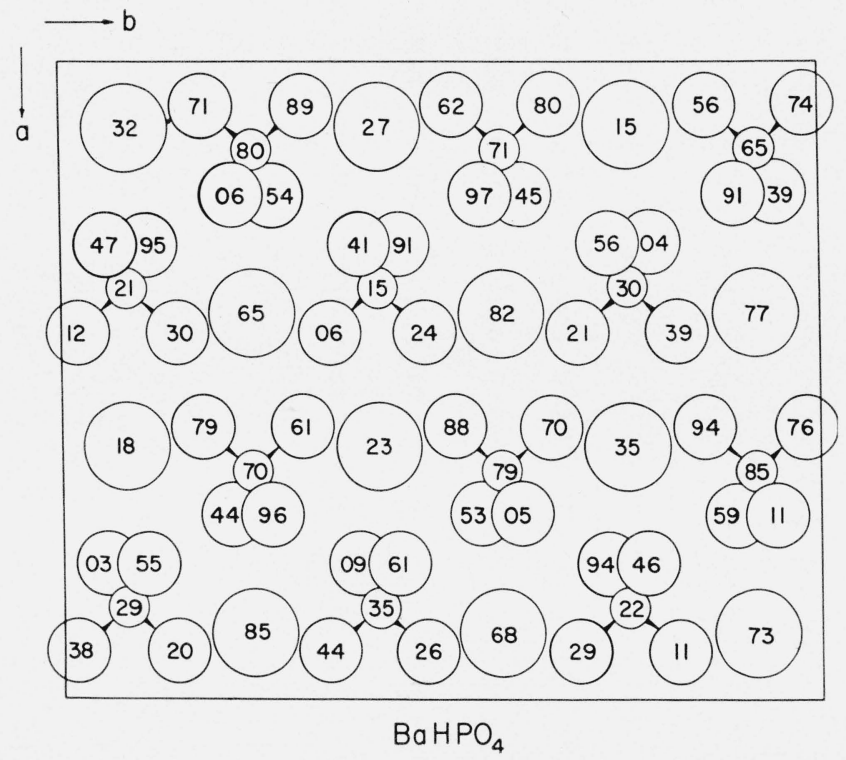

Figure 2. Projection of the structure on the hk0 plane.

(Circles in decreasing order of size represent $\mathrm{Ba}, \mathrm{O}$, and $\mathrm{P}$, respectively.) Complete phosphate tetrahedra are shown, but the heights indicated refer to the position in the single unit cell.
At about $z=0.25$ and $z=0.75$ there are rows parallel to the $a$ axis of alternating $\mathrm{Ba}$ and $\mathrm{P}$ atoms. The atoms within each row are not perfectly alined, but vary somewhat in their $z$ parameters. Adjacent rows at a given $c$ level are separated by $b / 3$. The families of rows $c / 2$ apart are displaced from each other by $b / 6$. Thus the projection on the base plane shows six such rows, separated by $b / 6$. All phosphate tetrahedra are rotated by roughly $21^{\circ}$ about these row axes. The reference position of $0^{\circ}$ rotation is taken as that in which a twofold axis of symmetry relates all the oxygens of the tetrahedron, and two of these oxygens are superimposed on each other in the projection on 001. Successive tetrahedra within the same row are rotated through an angle of the same magnitude but opposite sign. Figure 2 also shows that in rows adjacent in the projection on the base plane all the tetrahedra are oriented in opposite directions.

The $\mathrm{P}$ atoms are each surrounded by four oxygen atoms in apparently undistorted tetrahedral configuration and at distances of $1.56 \mathrm{~A}$ within the limits of experimental error. A summary of all other coordination distances is given in figure 3 . Lines with two numbers indicate coordination with two separate tetrahedra at different heights. Each $\mathrm{Ba}$ atom is in sevenfold coordination with oxygen atoms at distances varying from 2.6 to $3.1 \mathrm{~A}$. (The sum of the atomic radii is $2.75 \mathrm{~A}$.) Three additional oxygen atoms are tied to each $\mathrm{Ba}$ atom if the coordination distance is extended to $3.5 \mathrm{~A}$. Beyond this distance there is a considerable jump to the next nearest neighbor at $4.2 \mathrm{~A}$. Because of the uncertainty in the oxygen positions, coordination distances are significant only to the nearest $0.1 \mathrm{~A}$.

In the larger coordination sphere of barium, each Ba atom is linked to the oxygen atoms of four phosphate tetrahedra by edge sharing and to the oxygen atoms of two more by corner sharing. The coordi-

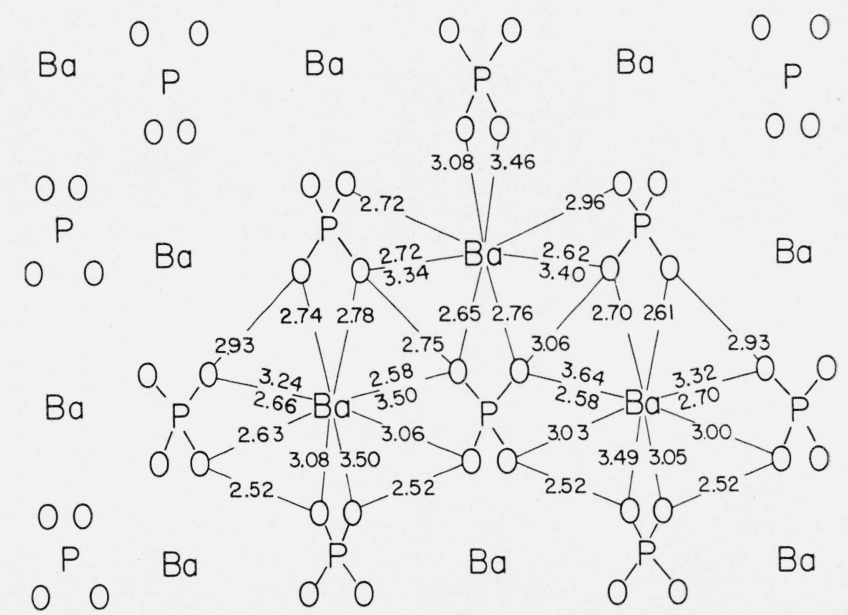

Figure 3. Coordination distances in projection on the $h k 0$ plane, indicating the three independent barium atoms. 
nation distances for each independent $\mathrm{Ba}$ atom are slightly different, but the general configuration around each is similar. This explains the presence of the pseudocell, because the pattern repeats at intervals of $a / 2$ and $b / 3$, and the contents of each pseudounit differ only in the relative displacements in the $c$ direction of the component atoms. Each phosphate tetrahedron has 2 oxygen atoms each linked to 2 different $\mathrm{Ba}$ atoms and the other 2 each bonded to $3 \mathrm{Ba}$ atoms.

The position of the hydrogen atom can be inferred from structural considerations. The experimentally observed $\mathrm{O}$ to $\mathrm{O}$ distances between adjacent tetrahedra are 3.1 and $3.2 \mathrm{~A}$ in one direction and two of $2.5 \mathrm{~A}$ in the opposite direction. It is generally assumed [10] that the extremely short bonds can be due only to an unusually large binding force, which must be ascribed to hydrogen bonding between these atoms. This would assign half the proton to each of the two $\mathrm{O}$ atoms bonded to only two barium atoms. No data could be obtained with X-rays on the symmetry of this hydrogen bond. This bonding would link phosphate tetrahedra in roughly a diagonal progression with translation of $c / 2$ and $b / 6$. The propagation direction is symmetrically opposed for tetrahedra separated by $a / 2$.

Structurally, there is a marked resemblance between the projection on (001) of $\mathrm{BaHPO}_{4}$ and the same projection of the triclinic $\mathrm{CaHPO}_{4}$. However, the coordination numbers of the metal atoms differ due to variation in the relative positions of the phosphate groups and the compounds are not isostructural.

\section{Summary}

The structure of $\mathrm{BaHPO}_{4}$ essentially consists of discrete phosphate tetrahedra, undistorted within the limits of measurement, held together by Ba ions and probably hydrogen bonding. The coordination sphere of the Ba atoms includes 10 oxygen atoms, 7 of which are bonded more firmly than the other 3 .

The author is indebted to Rose C. L. Mooney for suggesting this problem and helpful advice during the course of the investigation. Alvin Perloff prepared the crystals.

\section{References}

[1] G. MacLennan and C. A. Beevers, Acta Cryst. 8, 579 (1955).

[2] C. S. Lu, Rev. Sci. Instr. 14, 331 (1943).

[3] P. Groth, Chemische Kristallographie 2, 821 (Engelmann, Leipzig, 1908).

[4] Int. tables for X-ray crystallography, vol. I (The Kynoch Press, Birmingham, 1952).

[5] E. Bengtsson, Arkiv Kemi, Mineral. Geol., 15B, No. 7 (1941).

[6] R. C. L. Mooney, Atomic Energy Commission TID-5212, p. 165 (Technical Information Service, Oak Ridge, Tenn. Sept 1955).

[\%] H. T. Evans, Jr., J. Appl. Phys. 23, 663 (1952).

[8] D. W. J. Cruickshank, Acta Cryst. 2, 65 (1949).

[9] H. Lipson and W. Cochran, The determination of erystal structures (G. Bell \& Sons, Ltd., London, 1953).

[10] M. Gorman, J. Chem. Educ. 33, 468 (1956).

Washington, June 5, 1957. 